\title{
Germanium: From Its Discovery to SiGe Devices
}

\author{
E.E. Haller \\ Department of Materials Science and Engineering, University of California, Berkeley \\ and Materials Sciences Division, Lawrence Berkeley National Laboratory, Berkeley, CA \\ 94720 USA
}

\begin{abstract}
Germanium, element \#32, was discovered in 1886 by Clemens Winkler. Its first broad application was in the form of point contact Schottky diodes for radar reception during WWII. The addition of a closely spaced second contact led to the first all-solid-state electronic amplifier device, the transistor. The relatively low bandgap, the lack of a stable oxide and large surface state densities relegated germanium to the number 2 position behind silicon. The discovery of the lithium drift process, which made possible the formation of $\mathrm{p}$-i-n diodes with fully depletable i-regions several centimeters thick, led germanium to new prominence as the premier gamma-ray detector. The development of ultra-pure germanium yielded highly stable detectors which have remained unsurpassed in their performance. New acceptors and donors were discovered and the electrically active role of hydrogen was clearly established several years before similar findings in silicon. Lightly doped germanium has found applications as far infrared detectors and heavily Neutron Transmutation Doped (NTD) germanium is used in thermistor devices operating at a few milliKelvin. Recently germanium has been rediscovered by the silicon device community because of its superior electron and hole mobility and its ability to
\end{abstract}


induce strains when alloyed with silicon. Germanium is again a mainstream electronic material.

\section{Introduction}

The history of the science and technology of the chemical element germanium is at the same time the story of the transition from the "Physics of Dirt" to the birth of modern semiconductor physics and the story of the beginning of solid state electronics. The demonstration of the germanium point contact transistor on Christmas Eve 1947 by J. Bardeen and W. Brattain followed shortly by the invention of the germanium junction transistor by W. Shockley represents the beginning of the "Semiconductor Age," the successor to the Stone-, Bronze- and Iron Ages. In this brief review the major stages of the evolution of germanium from an element predicted by D.I. Mendeleev and named ekasilicium to today's use in high speed silicon devices will be visited. Limited space here does not allow for a detailed account of all the fascinating developments associated with this unusual element but key references will be used to guide the reader to major sources of information. This review is by no means comprehensive but it is an account based on personal choices and on numerous discussions with senior colleagues who played a role in some of these developments. It is with great pleasure that I recount the past 120 years of germanium history.

\section{Discovery of Germanium and Early History}

In 1871 D.I. Mendeleev predicted the existence of an element in the IVa column of his table of elements between the known elements silicon and tin. He called the unknown 
element eka-silicon. Fifteen years later, in 1886, Clemens Alexander Winkler found the missing element in the silver-rich mineral argyrodite and called it germanium (Fig. 1). Winkler was a renowned inorganic chemist at the Bergakademie (School of Mines) in Freiberg, Germany [1]. It took him only a few months to determine the major physical and chemical properties of the new element and he published his findings in a detailed 52-page article on August 14, 1886 [2]. Mendeleev had predicted different properties for his eka-silicon and tried to convince Winkler that he may have found something new but definitely not his eka-silicon. Winkler prevailed!

The year 1886 was rich in discoveries and novelties. In addition to the discovery of germanium, the first four-wheel motor car was built by Daimler-Benz, Coca Cola was formulated in Atlanta, Walter Schottky who developed the theory of the metalsemiconductor junction was born and patents for the mass production of aluminum were filed in the USA and Great Britain.

The years following the discovery of germanium did not lead to any major scientific findings or technological applications for this rare, expensive, brittle and metal-like element. In 1923 F.W. Aston found the three most abundant of the five stable isotopes, namely ${ }^{70} \mathrm{Ge},{ }^{72} \mathrm{Ge}$ and ${ }^{74} \mathrm{Ge}[3]$. Up to the late 1930 s germanium was believed to be a poorly conducting metal. This misunderstanding has persisted in some quarters to the present day: the boxes in which polycrystalline bars of germanium are shipped from the factory are still labeled in large bold letters, "Germanium Metal." 


\section{Reproducible Results in the 1940s}

The study and understanding of the physics of semiconductors progressed slowly in the $19^{\text {th }}$ and early $20^{\text {th }}$ centuries. Karl Lark-Horovitz wrote a condensed account of early experiments with semiconductors in his article, "The New Electronics" [4]. Impurities and defects simply could not be controlled to the degree necessary to obtain reproducible results. This led influential physicists, including W. Pauli and I. Rabi, to comment derogatorily on the "Physics of Dirt" [5,6]. The interest in semiconductors was kept alive, however, by the widespread use of crystal radios which used a fine metal point contact to a galena crystal $(\mathrm{PbS})$ acting as the radiofrequency rectifier. Ferdinand Braun had discovered rectification in 1874 [7].

World War II turned semiconductor physics into a respectable science. The beginning of this change can be dated back to 1942 when Karl Lark-Horovitz, Chair of the Physics Department at Purdue University, decided to work on germanium instead of galena or silicon. The driving force for semiconductor research was the need for a very high frequency rectifier and mixer to be used in radar receivers. Point contact rectifiers had a very low capacitance and could, in principle, function up to several GHz [8] (Fig. 2).

Lark-Horovitz's choice of germanium as the rectifier crystal shows exceptional intuition and judgment. He reasoned that germanium with a melting point $\sim 500^{\circ} \mathrm{C}$ lower than that of silicon would have a better chance of being purified to sufficiently low levels. Furthermore, germanium is chemically less reactive than silicon. It also would be more 
stable than compounds with volatile components and would not contain stoichiometryrelated defects. In a short three years the Purdue University group transformed the "Physics of Dirt" into a quantitative science [9]. Lark-Horovitz summarized the Purdue results in a report with a ten-point summary [10]. A few of the findings were:

1. Germanium of high purity has been prepared by reduction from pure oxide. ...B, $\mathrm{Al}, \mathrm{Ga}$, In all produce P-type germanium semiconductors. N, P, As, Sb and Sn and other elements produce $\mathrm{N}$-type germanium semiconductors.

2. Hall effect and thermoelectric power measurements and sign of rectification determine the sign of the carrier. Both Hall effect and thermoelectric power become negative at high temperature for all samples, indicating.... $* * *$

7. Germanium semi-conductors containing $\mathrm{P}$ or $\mathrm{Sb}$ can be used in microwave mixer crystals, comparing well in performance to silicon crystals.

$* * *$

9. Various types of photo effects have been observed.... $* * *$

The Purdue group also showed that ionized impurity scattering dominated carrier mobility at low temperatures. What they missed was the phenomenon of minority carrier injection, a key ingredient to the discovery of transistor action. A further point worth mentioning is the fact that all semiconductor studies were performed with polycrystalline 
samples! Purdue has remained at the forefront of semiconductor research, a legacy of the great pioneer Karl Lark-Horovitz.

\section{Point Contact Diodes and Transistors}

The histories of point contact diode mixers for radar reception $[8,9]$ and of the point contact transistor $[11,12,13]$ cannot be covered here in detail. For this brief review it is important to realize that germanium was in many respects the ideal semiconductor for the job. True, the bandgap of $0.7 \mathrm{eV}$ was on the low side, leading to intrinsic conduction at slightly elevated temperatures. Also, the oxide of germanium was not as stable as that of silicon and worse, the surface state density of oxidized germanium was far higher than the one for silicon. Based on the research at Purdue University and several other academic and industrial laboratories, germanium had become a well-controlled and wellunderstood semiconductor. Indeed, the first point contact transistor, invented by J. Bardeen and W.H. Brattain and officially introduced in December 23, 1947, was built with a slab of polycrystalline germanium from Purdue (Fig. 3)! Unfortunately, the two very fine point contacts pressed onto a germanium surface did not form a mechanically stable configuration nor was it able to carry large currents. W. Shockley's invention of the junction transistor, both p-n-p and n-p-n, remedied both shortcomings of the point contact transistor. The invention of the germanium transistor has been one of the most important events in shaping modern day life. There is the time before and the time after this invention. It is hard to come up with any modern day activity which is not influenced by the device called the transistor. 
The invention of the transistor led to a rapid development of all the necessary fabrication technologies. The exception was single crystal growth. In hindsight it is hard to believe that W. Shockley refused to offer space and support for a germanium crystal growth effort. He reasoned that since polycrystalline germanium had been satisfactory for the radar mixer diodes, the point contact and junction transistors, why embark on an expensive single crystal growth program? It took Gordon K. Teal well over a year to convince the Bell Labs leadership that growing large single crystals would become an important ingredient in a successful transistor mass production effort. Finally in 1950 Teal and Little reported on their crystal growth method [14]. They had designed and built a melt growth apparatus along the lines of Jan Czochralski's original idea $[15,16]$ (Fig. 4).

Germanium purification by chemical methods led to crystals with net-dopant concentrations as low as $10^{14} \mathrm{~cm}^{-3}$, an impressive result. Impurity segregation-based physical purification such as zone-melting invented by W. Pfann, [17] led to further improvements. Doping techniques based on melt-doping, alloying and diffusion were developed. The semiconductor technology became a worldwide endeavor and transistors began to encroach on the vacuum tube dominated electronics. By the late 1950s many of the technological difficulties inherent to silicon had been overcome and the first planar transistor called "pioneer" was introduced by Fairchild Semiconductors in 1960. The end of the era of germanium transistors was in sight but not before J. Kilby at Texas Instruments invented his germanium integrated circuit (IC) on September 12, 1958 [18] (Fig. 5). R. Noyce at Fairchild Semiconductors also had the idea of integrating a number 
of components onto one silicon chip using the silicon dioxide as a mask on a silicon wafer. J. Hoerni, Noyce's colleague had shown that openings in $\mathrm{SiO}_{2}$ masks were convenient for defining areas for adding donors or acceptors to build diodes and transistors in a planar fashion. Today's ICs are built using Noyce and Hoerni's ideas (Fig. 6).

\section{Applications of Germanium in Nuclear Physics: GeLi and hpGe Detectors}

As the germanium transistor age came to an end, a new application outside electronics and solid state physics arose. Nuclear physics was booming in the late 1950s and early 1960s. There was an urgent need to develop nuclear radiation spectrometers with good energy resolution. Scintillation detectors such as NaI had good sensitivity but very poor energy resolution. Freck and Wakefield demonstrated the first lithium-drifted germanium p-i-n detector [19]. It had an energy resolution of $3.2 \%$ for $663 \mathrm{keV}$ gamma rays of ${ }^{137}$ Cs. A year later Tavendale and Ewan published a paper with a resolution of $0.45 \%$ for $1.333 \mathrm{MeV}$ gamma rays from ${ }^{60} \mathrm{Co}[20]$.

The Tavendale-Ewan device was very impressive. Operated at liquid nitrogen temperatures it withstood a reverse bias of $450 \mathrm{~V}$ at a leakage current of $10^{-10} \mathrm{~A}$. It had a depletion depth of $8 \mathrm{~mm}$. The race for bigger and better GeLi detectors accelerated worldwide. I conducted my Ph.D. thesis research at the University of Basel, Switzerland, studying the very large, bare surfaces of our own GeLi detectors. Using monoenergetic

internal conversion electrons of ${ }^{207} \mathrm{Bi}$, we probed the charge collection along the depletion layer [21]. The p-type single crystals of germanium came from Metallurgie 
Hoboken-Overpelt in Olen, Belgium. The desire for ever larger detectors was insatiable. Planar detectors made from germanium single crystals of several $\mathrm{cm}$ in diameter and depletion layers over one $\mathrm{cm}$ were soon too small and were superseded by the coaxial geometry devices. One of the leading groups in the field worked in Strasbourg, France under the guidance of Professor P. Siffert, the founder and longtime president of EMRS. I vividly remember our visits to his impressive laboratories and his great and generous hospitality.

Just as in 1942 when Karl Lark-Horovitz decided to work on germanium instead of galena or silicon, based on good scientific and technical reasons, so were there overwhelming reasons to use this semiconductor for gamma-ray detection. The large atomic number $\mathrm{Z}=32$ guaranteed good stopping power for gamma rays. The electron and hole mobilities $(\mu)$ and lifetimes $(\tau)$ were great (and still yield the best $\mu \tau$ products to this day!) and large detection volumes of several hundred $\mathrm{cm}^{3}$ could be achieved. However, there was one shortcoming. The Achilles Heel of GeLi detectors was their sensitivity to being warmed up inadvertently to room temperature. Without a sufficient electric field across the device the perfect compensation of acceptors by mobile lithium donors was lost and the energy resolution suffered badly. In most cases perfect compensation could be reestablished by an expensive, time consuming re-drifting process. During the 1960s several companies began to fabricate GeLi detectors leading to their widespread use. 
Around 1970 R.N. Hall at the General Electric Laboratories in Schenectady, New York suggested that by judicious choice of the proper materials it should be possible to grow large germanium single crystals with net-dopant concentrations in the $10^{10}$ to $10^{11}$ $\mathrm{cm}^{-3}$ range. Crystals of such purity would make the lithium drifting process superfluous. Hall's suggestion looked like a daunting task: a semiconductor with one electrically active impurity for every $4 \times 10^{11}$ to $4 \times 10^{12}$ germanium atoms, an 11 - to 12 -nines pure material! In early 1971 I joined the group of F.S. Goulding at the Radiation Laboratory in Berkeley, California. A member of the group, William L. Hansen had the necessary knowledge and the courage to embark on the development of this so-called ultra-pure germanium. Over time I evolved into the characterization expert while Bill was in charge of purification and crystal growth. There were weeks where five crystals were being grown and completely analyzed for dislocation density and distribution, net-dopant concentration along the whole crystal, and for dopant species identification using highresolution Photo-Thermal Ionization Spectroscopy (PTIS). The exceptionally close coupling between growth and characterization and the high throughput made possible a wide range of exploratory studies. We studied the effects of the gas forming the growth atmosphere and found that only pure hydrogen gave satisfactory results. The reason for this will become clear in the following section. We studied the effects of various types of silica and graphite crucibles containing the ultra-pure melt as well as the graphite susceptor supporting the crucible which also provided the coupling to the RF power source heating the melt. After a relatively short time Bill grew his first crystals with $\mid \mathrm{N}_{\mathrm{A}}$ $-\mathrm{N}_{\mathrm{D}} \mid \cong 2 \times 10^{10} \mathrm{~cm}^{-3}$, a world record at the time (Fig. 7). Radiation detector fabrication involved the formation of a n-type contact by lithium diffusion. The p-type contact was 
substituted by a metal Schottky barrier (gold, palladium or chromium) (Fig. 8). The ultra-pure germanium crystal growth and detector research and development effort was augmented by highly specialized low noise, high speed electronics resulting in sophisticated radiation detector systems. Over the years a large number of such systems were custom made for many experiments conducted all over the world [22].

Having purification, crystal growth and a broad array of characterization tools all under the same roof allowed us to explore a wide range of parameters and led to important discoveries. The following section contains information on some of these fascinating developments.

\section{Physics with Ultra-Pure Germanium}

This section bears the title of an article I wrote 25 years ago for Advances in Physics [23]. A follow-up article, now 20 years old, was published in Advances in Solid State Physics [24]. In the following section, the major findings will be summarized with the inclusion of important collaborations based on our high-purity material.

\subsection{Electron-Hole Drops in Germanium}

Shining an intensive laser onto a cold piece of germanium with the laser photon energy exceeding the bandgap leads to the formation of excitons which, at sufficiently high concentrations, condenses into an electron-hole plasma which can be described as a liquid. Introducing inhomogeneous strain split the germanium energy bands and led to millimeter-size electron-hole drops. The continuous decay of excitons made this new 
state of matter visible in the infrared. Figure 9 shows one of the earliest video images of an electron-hole drop in germanium [25]. It took less than a month to get this result published in Physical Review Letters, another record of sorts!

Some of the detailed studies of electron-hole drop physics required highly sensitive detectors. Small ultra-pure germanium p-i-n detectors were considered by several groups but were quickly rejected because the bandgap of liquid nitrogen cooled $\mathrm{p}-\mathrm{i}-\mathrm{n}$ detectors was larger than the energy of the electron-hole drop decay photons. Such photons would travel through the germanium undetected. Carson Jeffries who led these studies at UC Berkeley [26] had a clever idea. He heated the germanium detector from $77 \mathrm{~K}$ to $\sim 120$ K. This temperature rise reduced the bandgap sufficiently to detect the electron-hole drop radiation but it did not raise the leakage current enough to generate noise. When visitors asked what kind of detector he used, Jeffries spoke the truth: p-i-n germanium diodes. Nobody believed him and it kept UC Berkeley ahead of the competition for well over a year.

\subsection{Hydrogen and Impurity Complexes}

Hydrogen plays a crucial role in all semiconductor processing. Soaking of devices at moderate temperatures in forming gas, a mixture of nitrogen and hydrogen, was known to improve device characteristics. Frank and Thomas determined the diffusivity, solubility and permeability of hydrogen in germanium [27]. They found near the melting point and with an ambient pressure of 1 atm $\mathrm{H}_{2}$ a solubility near $10^{14} \mathrm{~cm}^{-3}$. Hydrogen can be purified exquisitely with a palladium diffusion cell and it reduces oxides. Importantly, no 
electrically active dopant species involving hydrogen had been found by that time. Experience with $\mathrm{p}$-i-n detectors quickly showed that only $\mathrm{H}_{2}$-atmosphere-grown crystals yielded high resolution detectors. Hydrogen played a mysterious role. The first proof of hydrogen involvement in the formation of a new shallow acceptor and a new shallow donor came when we grew a crystal in a $\mathrm{D}_{2}$ atmosphere and found small but measurable isotope-related shifts in the ground states [28]. We found that hydrogen "activated" silicon impurities forming shallow acceptors $(\mathrm{A}(\mathrm{H}, \mathrm{Si}))$ and oxygen impurities forming shallow donors $(\mathrm{D}(\mathrm{H}, \mathrm{O}))$.

Hall had discovered these acceptors and donors when rapidly quenching ultra-pure germanium samples from $450{ }^{\circ} \mathrm{C}$ down to room temperature [29]. Figure 10 displays a PTI spectrum of a p-type crystal grown in $\mathrm{H}_{2}$ and a n-type crystal grown in $\mathrm{D}_{2}$. Both contain ground state to bound excited state lines of the chemical acceptors $\mathrm{B}$ and $\mathrm{Al}$ and the donor P. The corresponding lines are located at precisely the same photon energies. In contrast, the lines of the acceptor $\mathrm{A}(\mathrm{H}, \mathrm{Si})$ and the donor $\mathrm{D}(\mathrm{H}, \mathrm{O})$ show an isotoperelated shift, proof for the presence of hydrogen in these centers. Crystals grown in a mixture of $\mathrm{H}_{2}$ and $\mathrm{D}_{2}$ only showed two sets of lines for each center species, proof for only one hydrogen atom or deuterium atom per center! Most interesting was the observation that the acceptor $\mathrm{A}(\mathrm{H}, \mathrm{Si})$ had a ground state splitting which indicated a lowering of the symmetry. The donor $\mathrm{D}(\mathrm{H}, \mathrm{O})$ on the other hand showed a very unusual ground state behavior under uniaxial stress. The carbon-related analog of $\mathrm{A}(\mathrm{H}, \mathrm{Si})$, the acceptor $\mathrm{A}(\mathrm{H}, \mathrm{C})$, was discovered as well. The novel centers could be discovered because of the 
ultra-purity and the superb sensitivity of PTIS conducted with Fast Fourier Transform spectroscopy.

In short succession other hydrogen-related centers were discovered. Double ( $\mathrm{Zn}, \mathrm{Be})$ and triple acceptors $(\mathrm{Cu})$ could be partially passivated with one or two hydrogen atoms, respectively [30] or fully passivated with two or three hydrogen atoms, respectively [31]. L.M. Falicov assisted us with sophisticated models and theoretical calculations [32] and J.M. Kahn eventually sorted out all the geometry-related electronic state questions of these hydrogen-related impurity complexes. Frequent discussions with A.K. Ramdas at Purdue [33] helped us enormously in understanding far IR spectroscopy of shallow levels in germanium [34]. There is now general agreement that the passivation of deep level centers by hydrogen leads to the exceptionally good charge collection properties of ultrapure germanium.

A very interesting puzzle was the acceptor center showing up in all dislocation-free, $\mathrm{H}_{2}$-grown crystals. This acceptor formed a very effective hole trap at $\mathrm{E}_{\mathrm{V}}+80 \mathrm{meV}$ (Fig. 11). Its concentration could be changed reversibly by thermal annealing over a wide range. With expert guidance from A. Seeger, we concluded that the center must be a divacancy-hydrogen complex $\left(\mathrm{V}_{2} \mathrm{H}\right)$, which when binding a second hydrogen atom, became neutral [35]. The existence of $\mathrm{V}_{2} \mathrm{H}$ is the reason why high-purity germanium crystals for radiation detector applications have to have a small number of dislocations $\left(10^{2}-10^{3} \mathrm{~cm}^{-2}\right)$ which absorb the vacancies created at high temperatures. 
It is quite obvious that dopant and impurity activation and passivation was firmly established in germanium several years before the hydrogen-passivation of boron in silicon was discovered, a fact which is either forgotten or ignored!

Several non-hydrogen-related phenomena were discovered and studied in high-purity germanium. For example, in nitrogen atmosphere-carbon crucible growth crystals, we discovered the acceptor $\mathrm{A}(\mathrm{N}, \mathrm{C})$ in a substitutional and an interstitial form. The two configurations can be exchanged reversibly, however, with very different time constants [36]. Overcharged double acceptors $\mathrm{Be}$ and triple acceptors $\mathrm{Cu}$ were created and studied through optical pumping [37,38]. The concentrations of carbon and of hydrogen in ultrapure crystals were determined by using radioactive ${ }^{14} \mathrm{C}$ or tritium during crystal growth, respectively, and making self-counting detectors $[39,40]$. All these discoveries and studies were made possible through the co-location of crystal growth and characterization and through collaborations with many outstanding colleagues.

Ultra-pure germanium was the far IR spectroscopist's dream material. Using PTIS we resolved ten additional high-lying bound excited states of shallow acceptors. Line widths of less than $10 \mu \mathrm{eV}$ could be achieved (Fig. 12).

\section{Far-Infrared Detectors and Bolometers}

On a Friday afternoon in the early 1980 s, several men wearing dark suits visited our laboratory. They wanted to know everything about germanium: purification, growth, doping, contacts and more. They wanted to develop extrinsic far infared (IR) 
photoconductor detectors for the first far IR space telescope, the Infrared Astronomical Satellite (IRAS). The matter was quite obviously very urgent. This was the beginning of our involvement with NASA and far IR detector research.

The far IR region of the electromagnetic spectrum from a few tens to hundreds of micrometers in wavelength is rich in information regarding chemical composition, star formation, interstellar dust, planet formation, accretion disks around young stars and more. Unfortunately the atmosphere is opaque in this far IR range. High altitude telescopes, telescopes on airplanes and space-borne telescopes progressively give better access to the far IR. Moderately doped germanium crystals, $5 \times 5 \times 5 \mathrm{~mm}^{3}$ in size and equipped with heavily doped ohmic contacts are highly sensitive photoconductors in this wavelength region. Years of research, modeling and development have led to a thorough understanding of photoconductor physics [41] and to several superb far IR astronomy instruments. The Spitzer Space Telescope, a liquid helium-cooled IR telescope on an earth orbit carries the instrument called MIPS (Multi-Imaging Photometer for Spitzer) [42] with a $32 \times 32$ array of gallium-doped germanium photoconductors. Mechanical stress can be applied to p-type germanium photoconductors to reduce the acceptor energy from $\sim 11 \mathrm{meV}$ to $6 \mathrm{meV}$, extending the photoconductive onset to $220 \mu \mathrm{m}$. MIPS carries such detectors in a $2 \times 20$ pixel array. Spectacular images of numerous astronomical objects have been and are currently being recorded. The IR images provide new information by "seeing" objects shrouded in dust [43]. 
For wavelengths beyond the reach of extrinsic photoconductors, a different germanium device is used. It is a temperature sensitive tiny piece of heavily doped germanium, a thermistor. Typical operating temperatures are below $100 \mathrm{mK}$, often just a few milliKelvin. In order to obtain resistivities in the $M \Omega$ range doping has to be close to the metal-insulator transition, in gallium-doped material $\sim 1.8 \times 10^{17} \mathrm{~cm}^{-3}$. Homogeneous doping can be obtained with the Neutron Transmutation Doping (NTD) technique. It was Karl Lark-Horovitz who wrote the first extensive account on the effects of interactions of nuclei and energetic electrons with semiconductors [44]. Thermal neutrons in a nuclear reactor are used to transmute ${ }^{70} \mathrm{Ge}$ into ${ }^{71} \mathrm{Ga}$ acceptors and ${ }^{74} \mathrm{Ge}$ into ${ }^{75}$ As donors [45]. Micro- and millimeter wave telescopes use arrays of NTD germanium thermistors. A large $\beta$ - double decay and neutrino experiment, CUORE, is at the planning stage. It will use over 2,500 NTD germanium thermistors glued to $5 \times 5 \times 5$ cubic inches $\mathrm{TeO}_{2}$ single crystals maintained at 5 milliKelvin $[46,47]$.

\section{Isotopically Controlled Germanium}

Neutral germanium has five stable isotopes: ${ }^{70} \mathrm{Ge}(20.5 \%),{ }^{72} \mathrm{Ge}(27.4 \%),{ }^{73} \mathrm{Ge}$ $(7.8 \%),{ }^{74} \mathrm{Ge}(36.5 \%)$ and ${ }^{76} \mathrm{Ge}(7.8 \%)$. Enriched or deliberately mixed isotopes enable unique studies. For example, Geballe and Hull showed in 1958 that an enriched ${ }^{74} \mathrm{Ge}$ single crystal had a 3 times higher peak thermal conductivity than a natural germanium crystal [48]. This experiment verified the prediction by Pomeranchuk made in 1942 [49]. The exorbitant costs of enriched isotopes kept experimentation with enriched isotopes at a minimum. This changed around the end of the Cold War when collaborations between Russian laboratories engaged in isotope separation, and labs in the West became possible. 
I remember the day we grew the first 600 gram $95 \%$ enriched, ultra-pure ${ }^{70} \mathrm{Ge}$ crystal, perhaps the only such crystal in the universe.

Using layered isotope structures and Secondary Ion Mass Spectrometry (SIMS), we conducted self-diffusion experiments. The ${ }^{70} \mathrm{Ge}$ isotope concentration profile in Fig. 13 (b) follows a complementary error function for 4.5 orders of magnitude [50]! Phonons were studied with Raman spectroscopy in isotope bulk and superlattices [51,52]. By incorporating ${ }^{16} \mathrm{O}$ in enriched single crystals of ${ }^{70} \mathrm{Ge},{ }^{73} \mathrm{Ge},{ }^{74} \mathrm{Ge}$ and ${ }^{76} \mathrm{Ge}$ the local vibrational mode spectra were selectively simplified. This led to the first determination of the energies of the $v_{2}$ levels [53]. The dependences of the direct and indirect bandgaps on the germanium isotope mass were measured [54]. The metal-insulator transition (MIT) was determined with high precision with a highly enriched ${ }^{70} \mathrm{Ge}$ crystal doped over a wide concentration range across the MIT with NTD [55]. Many other experiments followed with different semiconductors $[56,57]$. Because of the rapidly rising interest in SiGe alloys, we are just starting a program on diffusion in isotopically controlled, strained and unstrained SiGe multilayer structures [58].

\section{Germanium Speeds Up Transistors}

Three unique properties led silicon to its supreme position in the world of electronic circuits and devices: 1.) A bandgap of $1.1 \mathrm{eV}$ allows operation to temperatures several hundred degrees higher than for germanium; 2.) a stable oxide, $\mathrm{SiO}_{2}$, which protects device surfaces and acts as an effective mask in device manufacturing; and 3.) an extremely low surface state density at the $\mathrm{SiO}_{2}-\mathrm{Si}$ interface. It is the third property which 
allows millions of metal-oxide-semiconductor field effect transistors (MOSFET) to be built simultaneously on a silicon wafer. The oxide of germanium is not stable and the interface density of states is too high for MOSFETs.

The rapid improvements in silicon technology, i.e., doubling the number of devices per chip and doubling the speed every 18 months, also known as Moore's Law, have continued for the past 40 years. But dimensions have become so small that improvements are much harder to achieve at the rate we have become accustomed. "Device scaling" is in jeopardy. Improvements based on fundamental properties, not only on dimensions, have to be found. The mobility of electrons and holes is one such property. It is ultimately related to bandstructure. The bandstructures of silicon shows six equivalent conduction band minima and three valence band maxima all at the center of the Brillouin zone. The valence band tops are degenerate and the third one is split-off by $44 \mathrm{meV}$. Application of stress to a semiconductor profoundly affects the bandstructure. The six conduction band minima in silicon are no longer equivalent affecting intervalley scattering and the valence band degeneracy is lifted. Depending on the sign of the stress, the holes will reside in the lower or the higher effective mass band. The changes in bandstructure lead to changes in mobility. The electron mobility rises with stress because the intervalley scattering becomes smaller and the hole mobility increases when the effective mass becomes smaller. But how should one apply the appropriate amount of stress to millions of MOSFETs? There are several solutions, all very clever. In one approach a graded composition, relaxed $\mathrm{Si}_{1-\mathrm{x}} \mathrm{Ge}_{\mathrm{x}}$ epitaxial layer is deposited on a silicon wafer. The value of $\mathrm{x}$ gradually increases from 0 to 0.3 . The 
lattice constant increases correspondingly. Next a silicon layer forming the channel region of the MOSFET is grown. It will be biaxially strained in tension. The electron mobility increases up to a factor of 2. Similar enhancements are found for holes but at larger strains. Experimentation with $\mathrm{Si}_{1-\mathrm{x}} \mathrm{Ge}_{\mathrm{x}}$ epilayers, both strained and relaxed, started in the 1980s [59] and has led to commercial devices [60].

Bandstructure engineering for increased mobility of electrons and holes through strain, caused by the addition of germanium, has brought this element back full circle into mainstream electronic device technology. But the outlook for germanium may be even brighter. Comparing mobilities of bulk silicon and germanium, one sees that the electron mobility is higher by a factor of $\sim 2$ and the hole mobility by a factor of 4 (see Table I). Why not build a germanium MOSFET?

This is precisely what many groups are attempting [61]. Instead of a $\mathrm{SiO}_{2}$ gate dielectric, $\mathrm{GeON}$ is used and the device characteristics look promising. Just as for silicon MOSFETs, bandstructure engineering through strain can be applied to germanium MOSFETs. This in turn should lead to the ultimate mobility enhancements.

There are more details which have to be taken in account when discussing strained $\mathrm{Si}$, SiGe and Ge channel MOSFETs. The reader with an interest in this topic is referred to an excellent recent review [62]. 


\section{Conclusions}

An attempt has been made to review some of the highlights of the 120-year history of the element germanium. The full history would fill several books and choices had to be made. There can be no doubt that the invention of the point contact and the junction transistor is the most important milestone in this history. There are a number of important niche applications for germanium such as high resolution gamma-ray detectors, far IR detectors and low temperature thermistors. The return of germanium to mainstream electronic device design based on bandstructure engineering through strain is an interesting development. Much of our detailed understanding of semiconductors was created through studies with germanium. Ultra-pure germanium led among other things to the discovery of a number of electrically active, hydrogen-related centers. Most recently isotopically controlled structures led to new approaches to studying self- and dopant diffusion and new phonon physics could be studied with isotope superlattices. If history can be used as an indicator for future developments, there can be little doubt that germanium will continue to make important contributions to science and technology. The study of germanium nanocrystals may be the next chapter in this history [63].

\section{Acknowledgments}

It is my pleasure to thank A.K. Ramdas, W.L. Hansen and H.-J. Queisser for assisting me in finding the relevant sources for this brief history of germanium. I am indebted to W.L. Hansen for teaching me practically everything I know about semiconductor crystal purification, growth and characterization. He freely shares his encyclopedic knowledge with everyone. A.K. Ramdas introduced me to the art of far IR high resolution 
spectroscopy and has been a close collaborator for the past thirty years. H.-J. Queisser hosted me as a guest in the country whose name our chemical element of interest bears. He contributed to semiconductor science and technology during its golden age and knows more scientists and stories than anybody else I know. I thank M. Cardona for all the adventures we had in the field of isotopically controlled semiconductors. L.M. Falicov, who passed away in his prime, taught me and many of my students solid state theory and came up with new ideas and models to explain our unusual experimental results. Last but not least, I would like to thank all of my students and postdocs for their enthusiasm, creativity and all the hard work which led to many exciting results.

The work has been supported over many years by DOE, NASA and NSF. Recent research has been supported in part by U.S. NSF Grant No. DMR-0405472, and in part by the Director, Office of Science, Office of Basic Energy Sciences, Division of Materials Sciences and Engineering, of the U.S. Department of Energy under Contract No. DE-AC02-05CH11231. 


\section{References}

1. H.C.A. Winkler, A. Lissner, A. Lange, and R. Prokop, Clemens Winkler (a detailed biography, Akademie Verlag, Berlin, 1954.

2. Clemens Winkler, J. prak. Chemie, 34 (1886) 177; also J. prak. Chemie, 36 (1887) 177.

3. F.W. Aston, Nature, 111 (1923) 771.

4. K. Lark-Horovitz, in F.S. Brackett (Ed), The Present State of Physics, Proceedings of the AAAS Symposium, New York, Dec. 30, 1949, AAAS, Washington DC, 1950 , p. 57.

5. R. W. Cahn, Nature Materials, 1 (2002) 3.

6. R.J. Anderson, MRS Bulletin, March 1993 (1993) 96.

7. F. Braun, Ann. Phys. Chem., (2)153 (1874) 556, see also Ann. Phys. Chem., (3)1 (1877) 436.

8. H.C. Torrey and C.A. Whitmer, Crystal Rectifiers, MIT Radiation Laboratory Series, Vol. 15, McGraw-Hill, New York and London, 1948.

9. R. Bray, The Origin of Semiconductor Research at Purdue, Purdue University Physics Department Website:

(http://tesla.physics.purdue.edu/about_us/history/semi_conductor_research.shtml)

10. L. Hoddeson, E. Braun, J. Teichmann, and S. Weart, Out of the Crystal Maze, Oxford University, Press, New York and Oxford, 1992, p. 459.

11. W. B. Shockley, J. Bardeen, and W.H. Brattain, in Nobel Lectures, Physics 19421962, Elsevier, Amsterdam. 1964; (see also the Nobel Prize website, http://nobelprize.org/physics/laureates/1956/)

12. H. Queisser, The Conquest of the Microchip, Harvard University Press, Cambridge and London, 1988.

13. M. Riordan and L. Hoddeson, Crystal Fire, W.W. Norton and Co., Ltd., New York and London, 1997.

14. G.K. Teal and J.B. Little, Phys. Rev., 78 (1950) 647.

15. J. Czochralski, Z. Phys. Chemie, 92 (1918) 219.

16. H.E. Bridgers, J.H. Scaff, and J.N. Shive, Transistor Technology, Vol. 1, D. van Nostrand Co., Inc., Princeton, 1958.

17. W. G. Pfann, Zone Melting, $2^{\text {nd }}$ ed., John Wiley \& Sons, Inc, New York, 1966. 
18. J. Kilby, in Nobel Lectures, Physics 1996-2000, World Scientific Publishing Co., Singapore, 2002, p. 474.

19. D.V. Freck and J. Wakefield, Nature, 193 (1962) 669.

20. J. Tavendale and G.T. Ewan, Nucl. Instrum. Methods, 25 (1963) 185.

21. E. Baldinger and E.E. Haller, in P. Eichinger and G. Keil (Eds), Proc. Symp. Semiconductor Detectors for Nuclear Radiation, Munich, 1970, p. 9; E. Baldinger and E. E. Haller, Helv. Phys. Acta, 43 (1970) 833.

22. E. E. Haller and F. S. Goulding, in C. Hilsum (Ed), Handbook on Semiconductors, Vol. 4, $2^{\text {nd }}$ ed., Elsevier North-Holland Inc., New York, 1993, p. 937.

23. E. E. Haller, W. L. Hansen, and F. S. Goulding, Adv. Phys., 30 (1981) 93.

24. E. E. Haller, in P. Grosse (Ed), Festkörperprobleme/ Advances in Solid State Physics XXVI, Vieweg, 1986, p. 203.

25. J. P. Wolfe, W. L. Hansen, E. E. Haller, R. S. Markiewicz, C. Kittel, and C. D. Jeffries, Phys. Rev. Lett., 34 (1975) 1292.

26. C.D. Jeffries, Science, 189 (1975) 955.

27. R.C. Frank and J.E. Thomas, J. Chem. Phys. Solids, 16 (1960) 144.

28. E. E. Haller, Phys. Rev. Lett., 40 (1978) 584.

29. R.N. Hall, IEEE Trans. Nucl. Sci., NS-21, (1974) 260.

30. R. E. McMurray, Jr., N. M. Haegel, J. M. Kahn and E. E. Haller, Solid State Commun., 53 (1985) 1137.

31. J. M. Kahn, L. M. Falicov, and E. E. Haller, Phys. Rev. Lett., 57 (1986) 2077.

32. L. M. Falicov and E. E. Haller, Solid State Commun., 53 (1985) 1121.

33. A. K. Ramdas and S. Rodriguez, Rep. Prog. Phys., 44 (1981) 1297.

34. J. M. Kahn, R. E. McMurray, Jr., E. E. Haller, and L. M. Falicov, Phys. Rev. B, 36 (1987) 8001.

35. E. E. Haller, G. S. Hubbard, W. L. Hansen and A. Seeger, Inst. Phys. Conf. Ser., 31 (1977) 309.

36. E. E. Haller and R. E. McMurray, Jr., Physica B+C, 116 (1983) 349.

37. E. E. Haller, R. E. McMurray, Jr., L. M. Falicov, N. M. Haegel, and W. L. Hansen, Phys. Rev. Lett., 51 (1983) 1089. 
38. E. E. Haller, R. E. McMurray, Jr., N. M. Haegel, and L. M. Falicov, in J. D. Chadi, and W. A. Harrison (Eds), Proc. 17th International Conference on the Physics of Semiconductors, Springer, 1985, p. 679.

39. E. E. Haller, W. L. Hansen, P. Luke, R. McMurray, and B. Jarrett, IEEE Trans. Nucl. Sci., NS-29 (1982) 745.

40. W. L. Hansen, E. E. Haller, and P. N. Luke, IEEE Trans. Nucl. Sci., NS-29 (1982) 738.

41. N. M. Haegel and E. E. Haller, SPIE, 659 (1986) 188.

42. G. H. Rieke, E. T. Young, C. W. Engelbracht, D. M. Kelly, F. J. Low, E. E. Haller, J. W. Beeman, K. D. Gordon, J. A. Stansberry, K. A. Misselt, J. Cadien, J. E. Morrison, G. Rivlis, W. B. Latter, A. Noriega-Crespo, D. L. Padgett, K. R. Stapelfeldt, D. C. Hines, E. Egami, J. Muzerolle, A. Alonso-Herrero, M. Blaylock, H. Dole, J. L. Hinz, E. Le Floc'h, C. Papovich, P. G. Pérez-González, P. S. Smith, K. Y. L. Su, L. Bennett, D. T. Frayer, D. Henderson, N. Lu, F. Masci, M. Pesenson, L. Rebull, J. Rho, J. Keene, S. Stolovy, S. Wachter, W. Wheaton, M. W. Werner, and P. L. Richards, Astrophys. J. Suppl. Ser., 154 (2004) 25.

43. Consult the Spitzer website at http://www.spitzer.caltech.edu

44. K. Lark-Horovitz, in "Semiconducting Materials," H.K. Henisch (Ed), Proceedings of a Conference held in Redding (1950) under the auspices of IUPAP Inc., Butterworth Sci. Publ. LTD, London, 1951, p. 47.

45. E. E. Haller, N. P. Palaio, M. Rodder, W. L. Hansen, and E. Kreysa, in R. D. Larrabee (Ed), Proc. Fourth Intl. Conf. on Neutron Transmutation Doping of Semiconductor Materials, National Bureau of Standards, Gaithersburg, MD, June 12, 1982, Plenum Press, 1984, p. 21.

46. C. Arnaboldi, F. T. Avignone III, J. Beeman, M. Barucci, M. Balata, C. Brofferio, C. Bucci, S. Cebrian, R. J. Creswick, S. Capelli, L. Carbone, O. Cremonesi, A. de Waard, E. Fiorini, H. A. Farach, G. Frossati, A. Giuliani, D. Giugni, P. Gorla, E. E. Haller, I. G. Irastorza, R. J. McDonald, A. Morales, E. B. Norman, P. Negri, A. Nucciotti, M. Pedretti, C. Pobes, V. Palmieri, M. Pavan, G. Pessina, S. Pirro, E. Previtali, C. Rosenfeld, A. R. Smith, M. Sisti, G. Ventura, M. Vanzini, and L. Zanotti, Nucl. Instrum. Methods A, 518 (2004) 775.

47. P. Gorla, R. Ardito, C. Arnaboldi, D.R. Artusa, F.T. Avignone III, M. Balata, I. Bandac, M. Barucci, J. Beeman, C. Brofferio, C. Bucci, S. Capelli, F. Capozzi, L. Carbonec, S. Cebrianb, O. Cremonesi, R.J. Creswick, M. Dolinski, A. de Waard, H.A. Farach, F. Ferroni, E. Fiorini, G. Frossati, C. Gargiulo, A. Giuliani, E. Guardincerri, T. Gutierrez, E.E. Haller, I.G. Irastorza, E. Longo, G. Maier, R. Maruyama, R.J. McDonald, S. Morganti, A. Morales, S. Nisi, E.B. Norman, A. Nucciotti, E. Olivieri, P. Ottonello, M. Pallavicini, V. Palmieri, E. Pasca, M. Pavan, M. Pedretti, G. Pessina, S. Pirro, E. Previtali, B. Quiter, L. Risegari, C. Rosenfeld, 
S. Sangiorgio, M. Sisti, A.R. Smith, Toffanin, L. Torres, G. Ventura and N. Xu, Nucl. Phys. B (Proc. Suppl.), 150 (2006) 214.

48. T.H. Geballe and G. Hull, Phys. Rev., 110 (1958) 773.

49. I. Pomeranchuk, J. Phys. (Moscow) 6 (1942) 237.

50. H. Fuchs, W. Walukiewicz, E. E. Haller, W. Dondl, R. Schorer, G. Abstreiter, A. I. Rudnev, A. V. Tikhomirov, and V. I. Ozhogin, Phys. Rev. B, 51 (1995) 16817.

51. H. D. Fuchs, C. H. Grein, C. Thomson, M. Cardona, W. L. Hansen, K. Itoh, and E. E. Haller, Phys. Rev. B, 43 (1991) 4835.

52. J. Spitzer, T. Ruf, M. Cardona, W. Dondl, R. Schorer, G. Abstreiter and E. E. Haller, "Raman Scattering by Optical Phonons in Isotopic ${ }^{70}(\mathrm{Ge})_{n}{ }^{74}(\mathrm{Ge})_{\mathrm{n}}$ Superlattices," Phys. Rev. Lett., 72 (1994) 1565.

53. A.J. Mayur, M. Dean Sciacca, M.K. Udo, A.K. Ramdas, K. Itoh, J. Wolk, and E.E. Haller, Phys. Rev. B, 49 (1994) 16293.

54. C. Parks, A.K. Ramdas, S. Rodriguez, K.M. Itoh and E.E. Haller, Phys. Rev. B 49 (1994) 14244; see also: A.K. Ramdas, S. Rodriguez, S. Tsoi, and E.E. Haller, Solid State Commun. 133 (2005) 709.

55. K. M. Itoh, E. E. Haller, J. W. Beeman, W. L. Hansen, J. Emes, L. A. Reichertz, E. Kreysa, T. Shutt, A. Cummings, W. Stockwell, B. Sadoulet, J. Muto, J. W. Farmer, and V. I. Ozhogin, Phys. Rev. Lett., 77 (1996) 4058.

56. E. E. Haller, Appl. Phys. Reviews, J. Appl. Phys., 77 (1995) 2857.

57. E. E. Haller, Solid State Commun., 133 (2005) 693; and other articles in this special issue of Solid State Communications.

58. H. H. Silvestri, H. Bracht, J. Lundsgaard Hansen, A. Nylandsted Larsen, and E. E. Haller, Semicond. Sci. Technol., 21 (2006) 758.

59. G. Abstreiter, H. Brugger, T. Wolf, H.J. Herzog, Phys. Rev. Lett., 54 (1985) 2491.

60. T. Ghani, M. Armstrong, C. Auth, M. Bost, P. Charvat, G. Glass, T. Hoffmann, K. Johnson, C. Kenyon, J. Klaus, B. McIntyre, K. Mistry, A. Murthy, J. Sandford, M. Silberstein, S. Sivakumar, P. Smith, K. Zawadzki, S. Thompson, and M. Bohr, IEEE IEDM, 2003, p. 978.

61. H. Shang, H. Okorn-Schmidt, K.K. Chan, M. Copel, J.A. Ott, P.M. Kozlowski, S.E. Steen, S.A. Cordes, H.-S. P. Wong, E.C. Jones, and W.E. Haensch, IEEE IEDM, 2002, p. 441. 
62. M.L. Lee, E.A. Fitzgerald, M.T. Bulsara, M.T. Currie, and A. Lochtefeld, J. Appl. Phys., 97 (2005) 011101.

63. I.D. Sharp, Q. Xu, C.Y. Liao, D.O. Yi, J.W. Beeman, Z. Liliental-Weber, K.M. Yu, D.N. Zakharov, J.W. Ager III, D.C. Chrzan, and E.E. Haller, J. Appl. Phys., 97 (2005) 124316. 
Table I. Mobilities in bulk silicon and germanium at room temperature

\begin{tabular}{|c|c|c|}
\hline & Si & Ge \\
\hline$\mu_{\mathrm{e}}\left(\mathrm{cm}^{2} / \mathrm{V} \cdot \mathrm{s}\right)$ & 1500 & 3900 \\
\hline$\mu_{\mathrm{h}}\left(\mathrm{cm}^{2} / \mathrm{V} \cdot \mathrm{s}\right)$ & 450 & 1900 \\
\hline
\end{tabular}




\section{Figure Captions}

Fig. 1. D.I. Mendeleev and C.A. Winkler at the meeting of the $100^{\text {th }}$ anniversary of the Prussian Academy of Science, Berlin, March 19, 1900.

Fig. 2. Crystal cartridge parts (Courtesy of Ref. 8).

Fig. 3. The first transistor fabricated by Bell Laboratories' scientists was this crude point-contact device, built with two cat's whiskers and a slab of polycrystalline germanium.

Fig. 4. Uniformity of crystal geometry obtainable with the pulling technique. (Courtesy of Ref. 16)

Fig. 5. The first integrated germanium circuit built by J. Kilby at Texas Instruments in 1958.

Fig. 6. This is the first page of Noyce's 1961 patent on the integrated circuit. Noyce used the planar processing technique to form $\mathrm{p}$ - $\mathrm{n}$ junctions beneath a silicion dioxide surface layer (labeled 5 in the drawings).

Fig. 7. The Lawrence Berkeley Laboratory ultra-pure germanium growth apparatus. A water-cooled RF-powered coil surrounds the silica envelope of the puller. About half of the $25 \mathrm{~cm}$ long crystal has been grown. 
Fig. 8. Ultra-pure germanium detector with closed-end coaxial contact geometry. The borehole reaches to within in $\sim 2 \mathrm{~cm}$ of the backsurface of the p-i-n device and forms one contact. The whole outside except the flat surface surrounding the hole forms the other contact. Large volume detectors with small capacitance can be achieved with the coaxial geometry. (Courtesy of P.N. Luke, Lawrence Berkeley National Laboratory)

Fig. 9. Photograph of a long-lived electron-hole drop in a 4-mm disk of pure germanium. The sample is mounted in a dielectric sample holder and stressed by a 1.8-mm-diam screw discernible on the left. The drop is the intense spot adjacent to the screw. The bright ring is drop-luminescence light scattered from the sample boundary. The bright line along the lower right crystal rim is scattered luminescence from an orientation mark along the $<100\rangle$ axis. The outer gray ring is the dielectric holder made visible by external illumination. (After Ref. 25)

Fig. 10. Photothermal Ionization spectra of hydrogen atmosphere grown crystal \#475 (ptype) and deuterium atmosphere grown crystal \#519 (n-type). The temperature was 8.0 K. The ground state to bound excited state peaks of the chemical acceptors Al and B and the chemical donor $\mathrm{P}$ line up perfectly. The lines of the acceptor $\mathrm{A}(\mathrm{H}, \mathrm{Si})$ and $\mathrm{A}(\mathrm{D}, \mathrm{Si})$ and of the donors $\mathrm{D}(\mathrm{H}, \mathrm{O})$ and $\mathrm{D}(\mathrm{D}, \mathrm{O})$ are affected by an isotope shift. (After Ref. 28) 
Fig 11. Hole concentration against reciprocal temperature $1 / \mathrm{T}$ of a dislocated and an undislocated Ge sample cut from the same crystal slice. The net impurity concentration of shallow acceptors and donors is equal for both samples. The $\mathrm{E}_{\mathrm{V}}+0.08 \mathrm{eV}$ acceptor only appears in the dislocation-free piece; its concentration depends on the annealing temperature. $\odot$ dislocation free; + dislocated. (After Ref. 34)

Fig. 12. Typical PTI Spectrum of ultra-pure germanium. The $5 \times 5 \times 5 \mathrm{~mm}^{3}$ piece of the crystal had two ion implanted contacts on opposite faces. The net-acceptor concentration is $2 \times 10^{10} \mathrm{~cm}^{-3}$. Because of the high resolution, the small lines of $\mathrm{B}$ and $\mathrm{Ga}$ can be seen clearly.

Fig. 13. Secondary Ion Mass Spectrometry (SIMS) profile of a ${ }^{\text {nat }} \mathrm{Ge} /{ }^{74} \mathrm{Ge} /{ }^{70} \mathrm{Ge} /{ }^{\text {nat }} \mathrm{Ge}$ substrate structure before (a) and after annealing for 55.55 hours at a temperature of 586 ${ }^{\circ} \mathrm{C}$ (b). The self-diffusion of the ${ }^{70} \mathrm{Ge}$ into the ${ }^{74} \mathrm{Ge}$ layer can be modeled with a simple complimentary error function to a very high level of precision. 


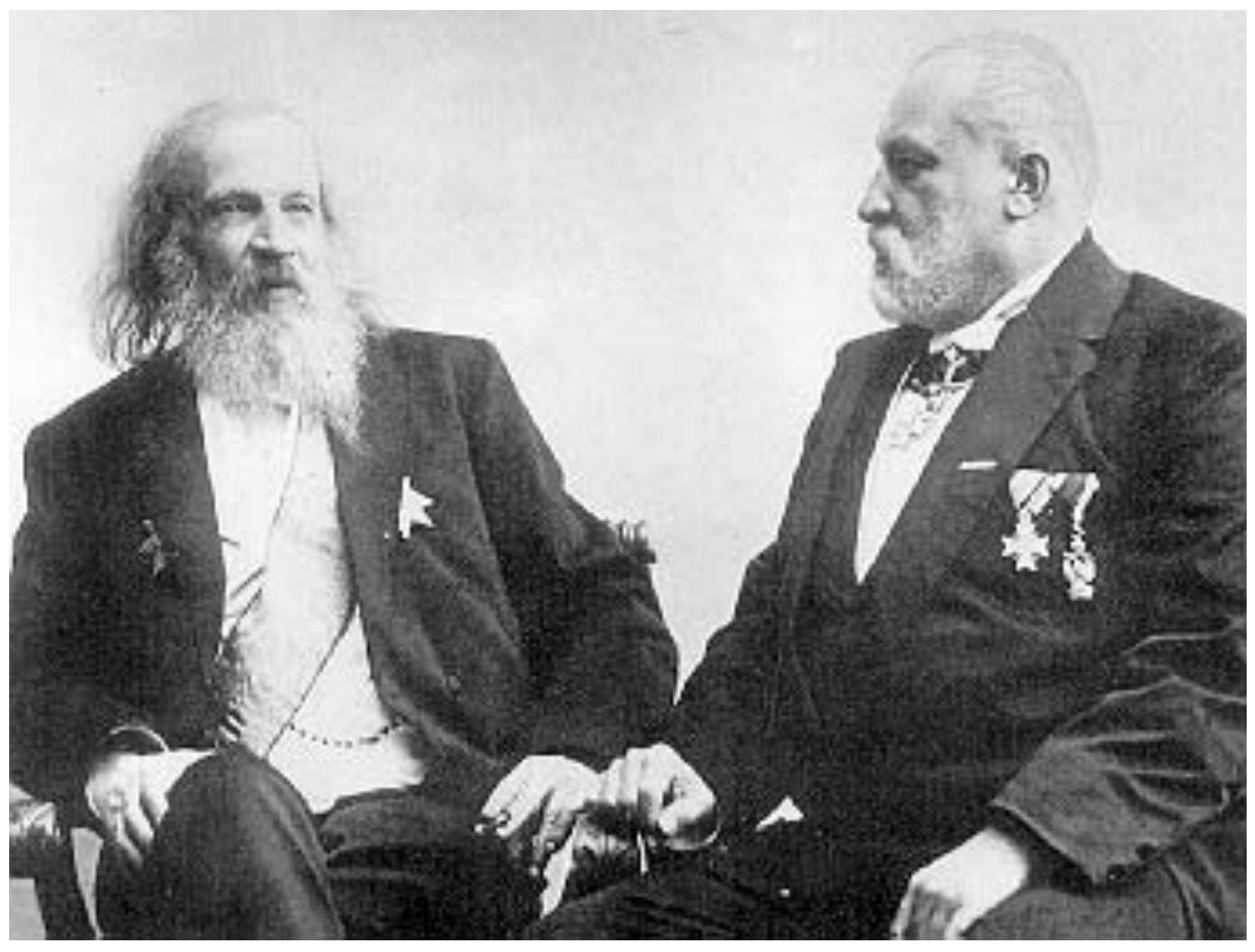

Figure 1 


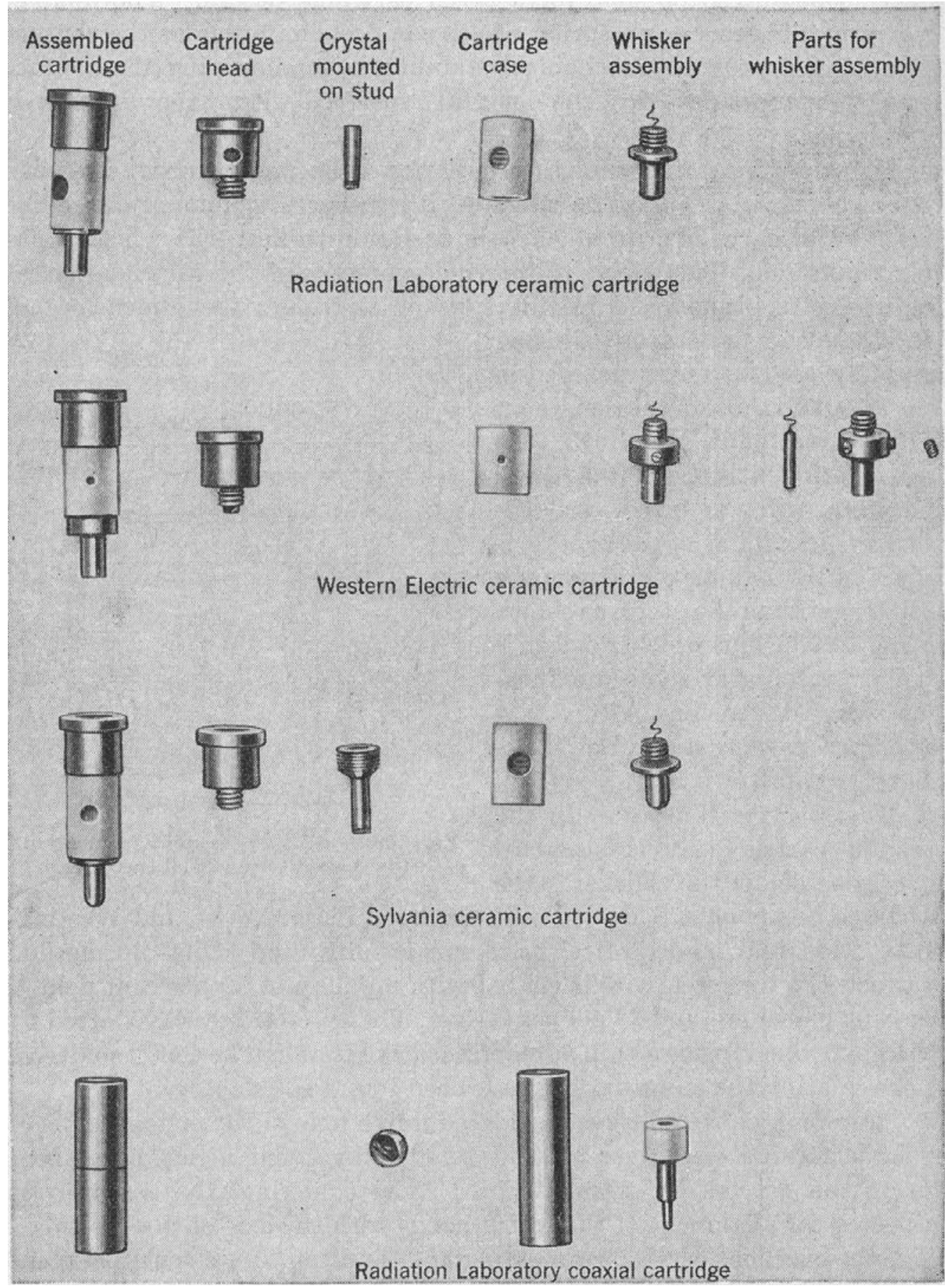

Figure 2. 


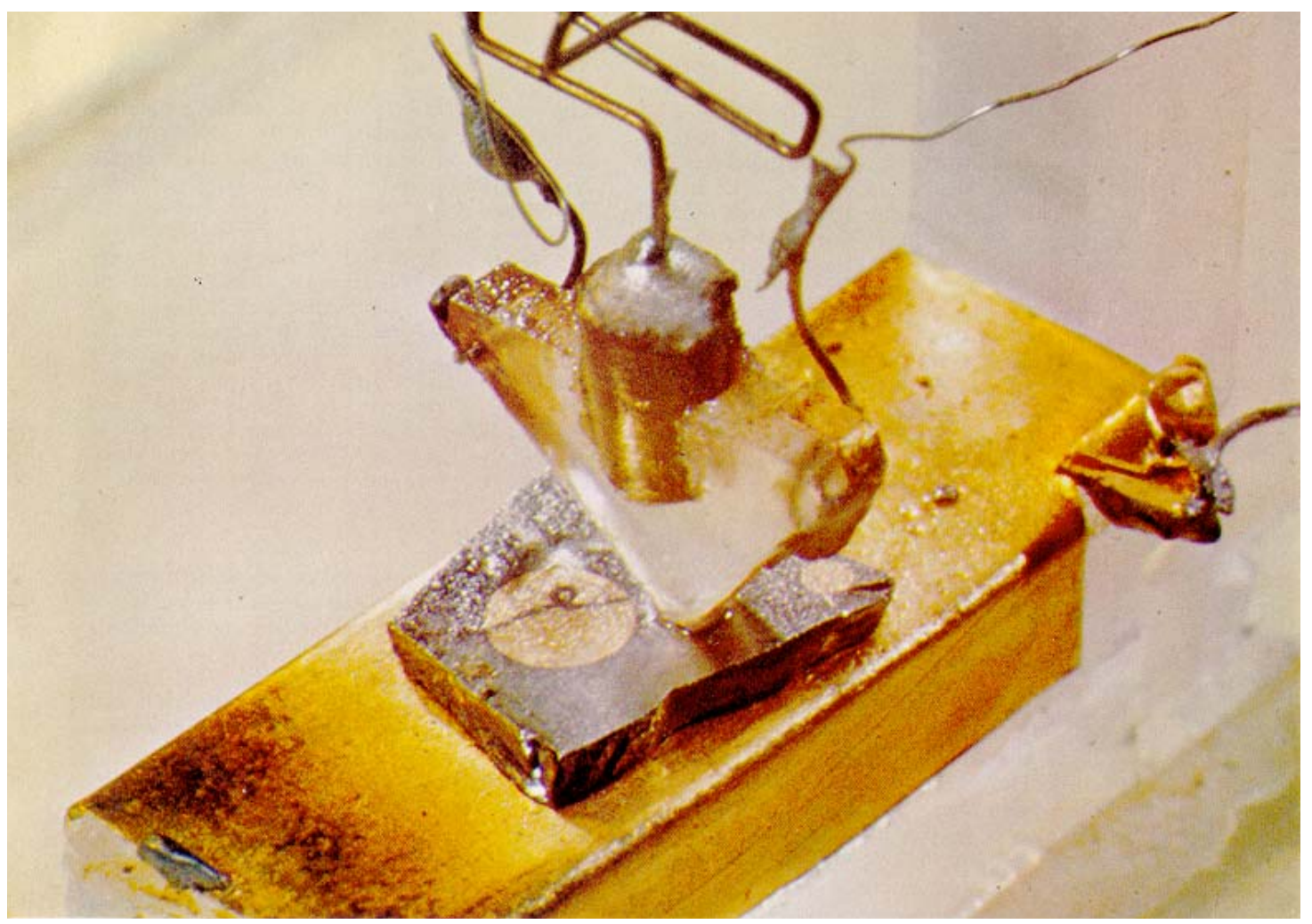

Figure 3. 


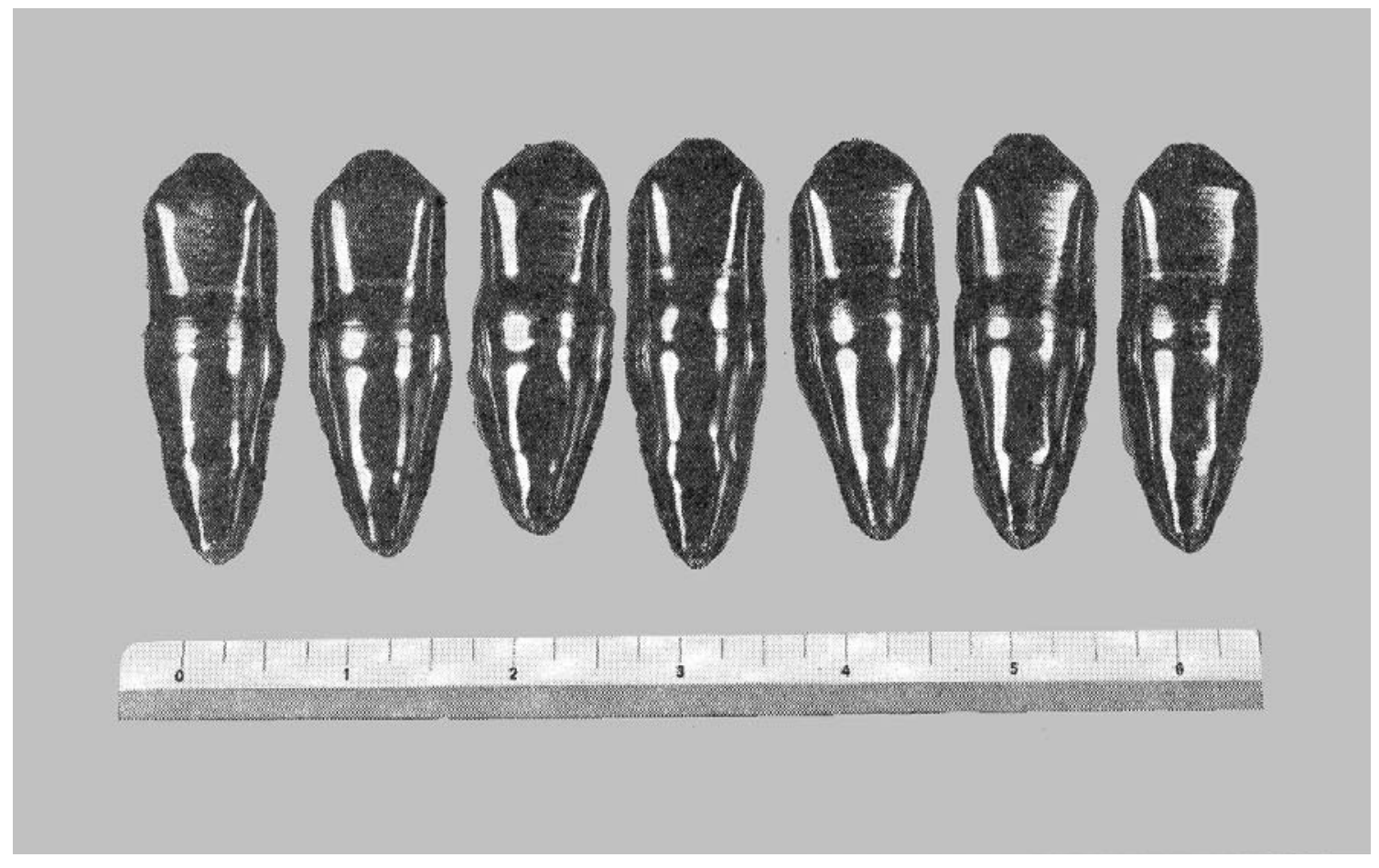

Figure 4. 


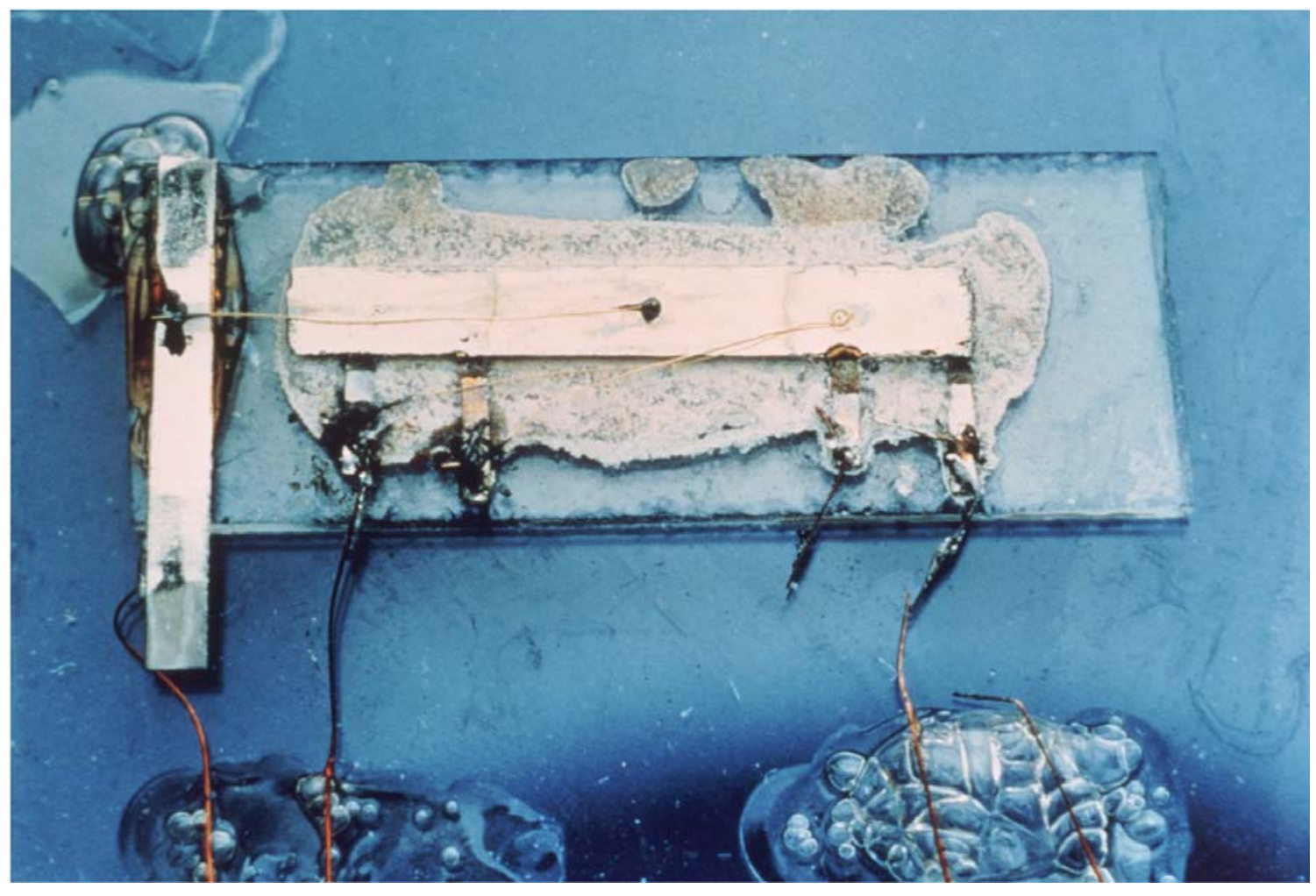

Figure 5. 


\section{April 25, 1961 \\ R. N. NOYCE \\ $2,981,877$ \\ SEMICONDUCTOR DEVICE-AND-LEAD STRUCTURE}

FLlod Juty 30, 1959

3 Sheets-Sheet 1
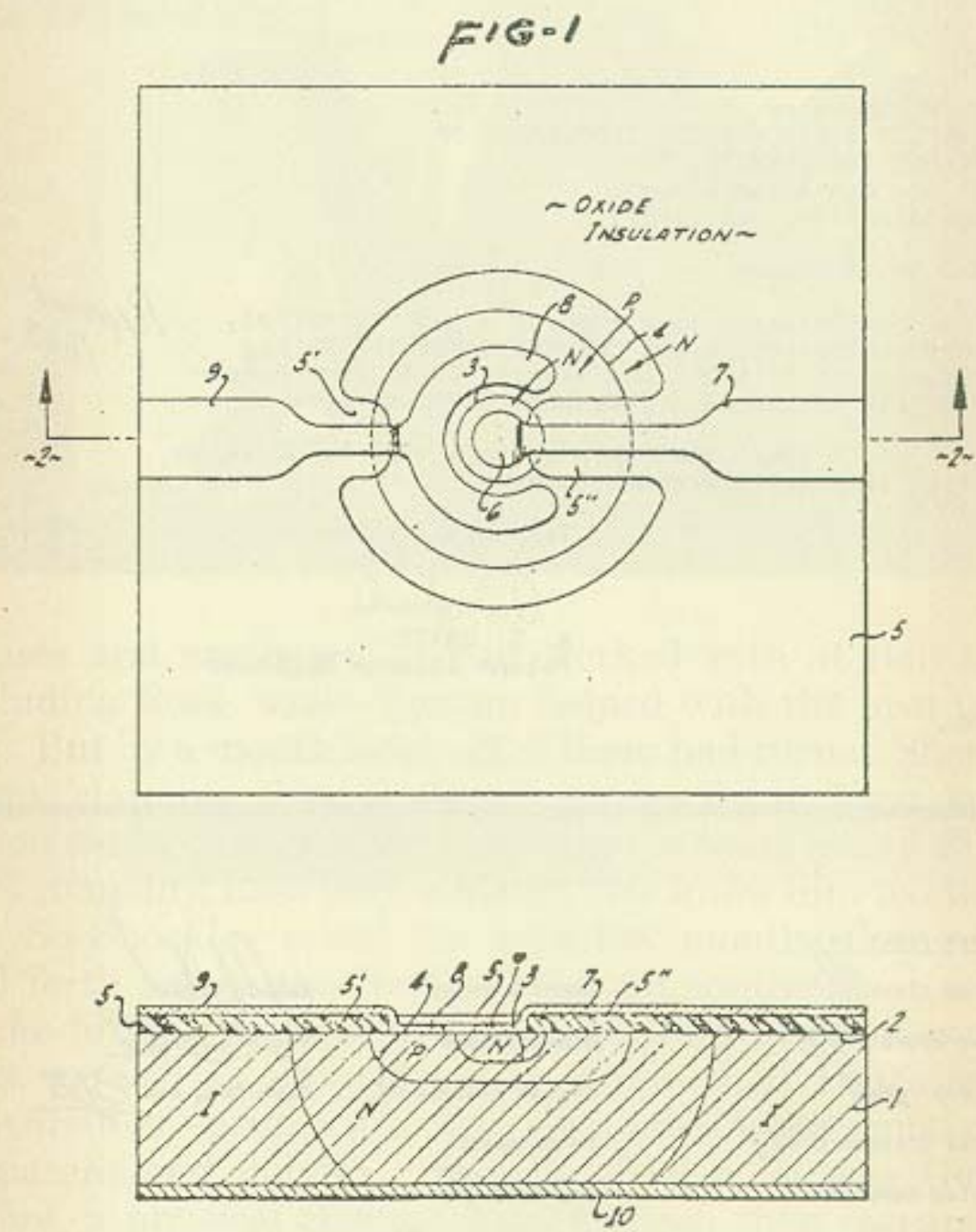

Fis-

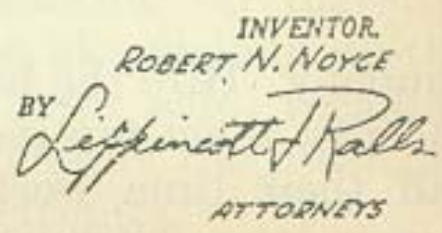

Figure 6. 


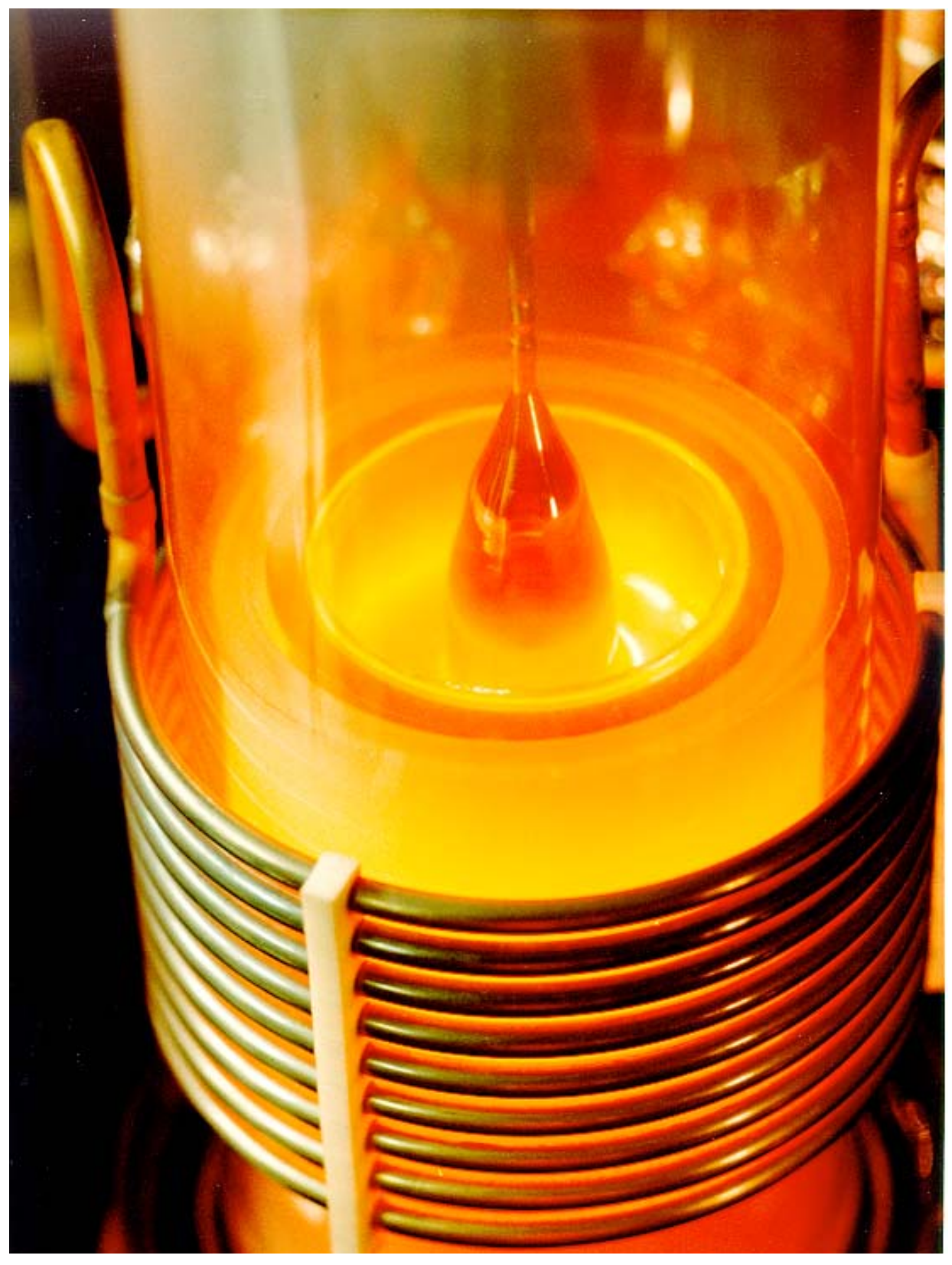

Figure 7. 


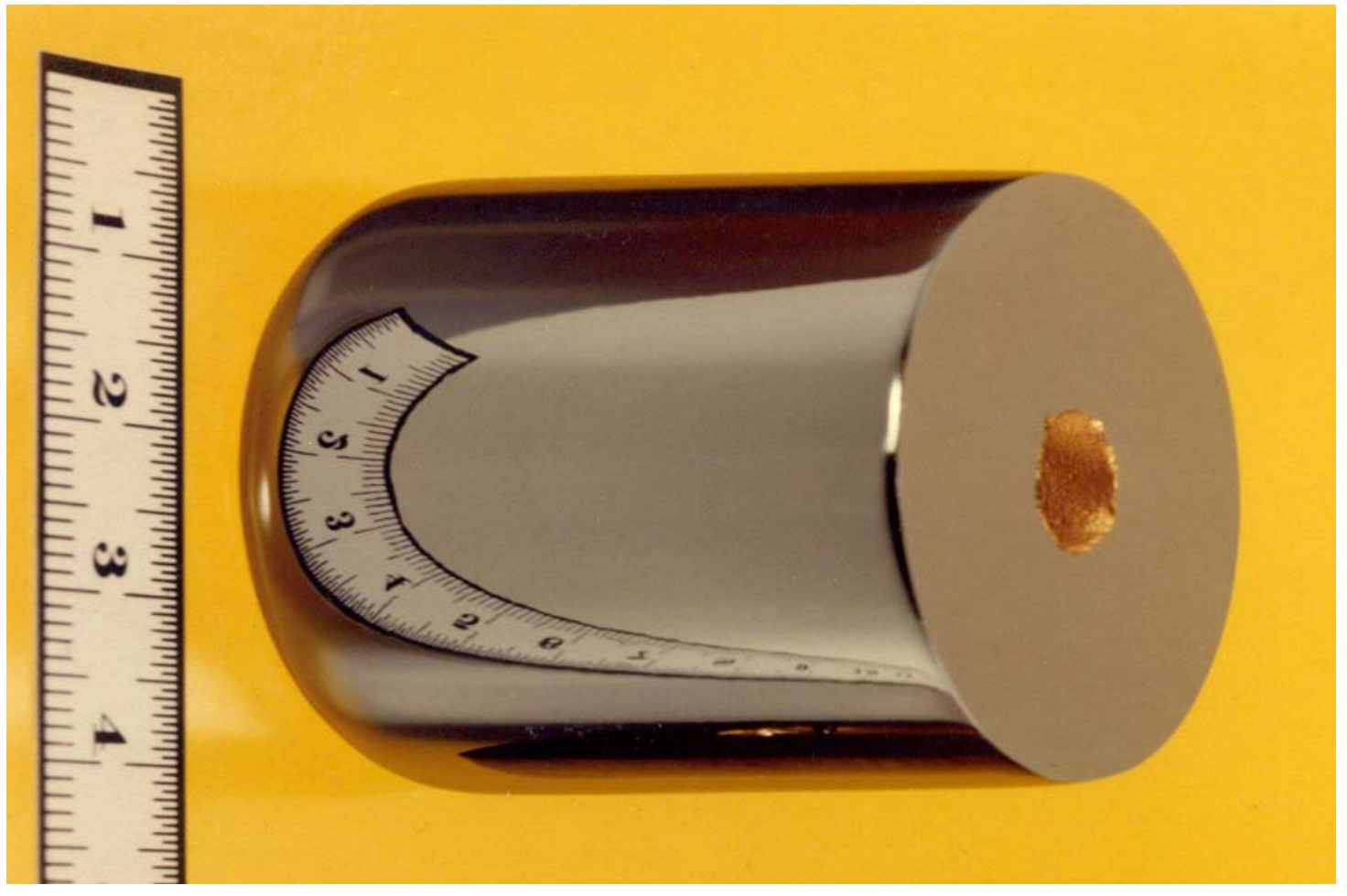

Figure 8. 


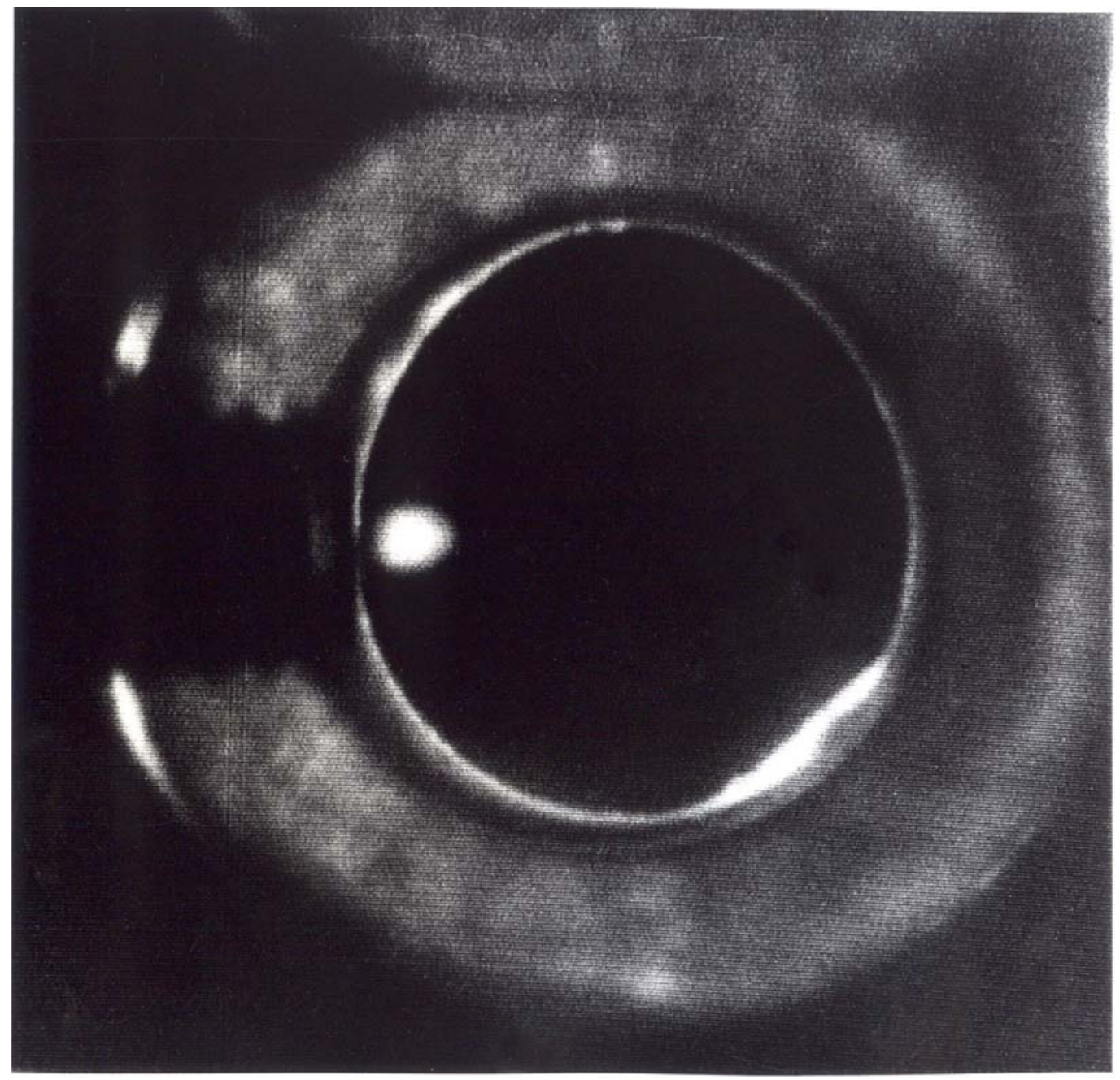

Figure 9. 


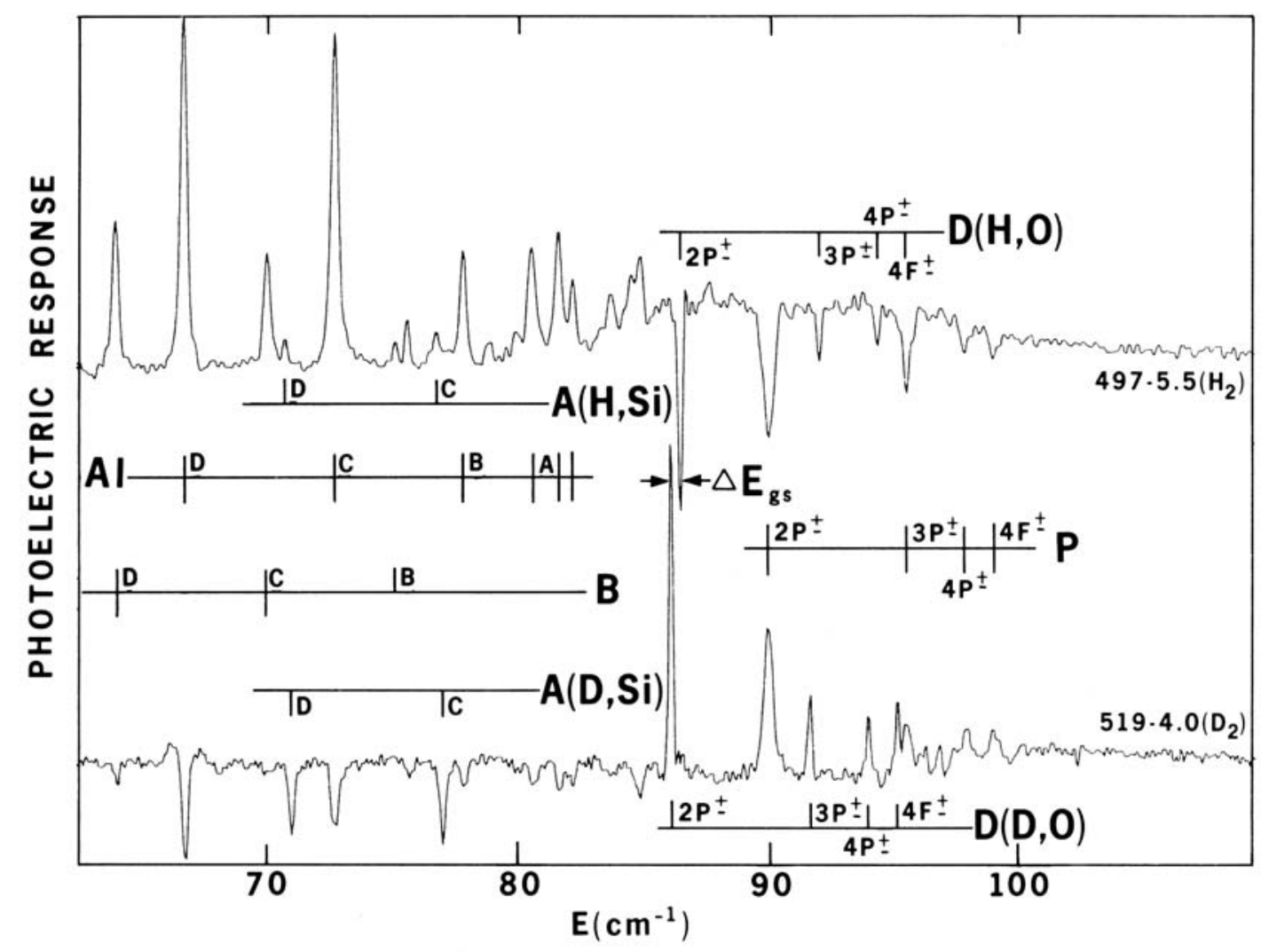

Figure 10. 


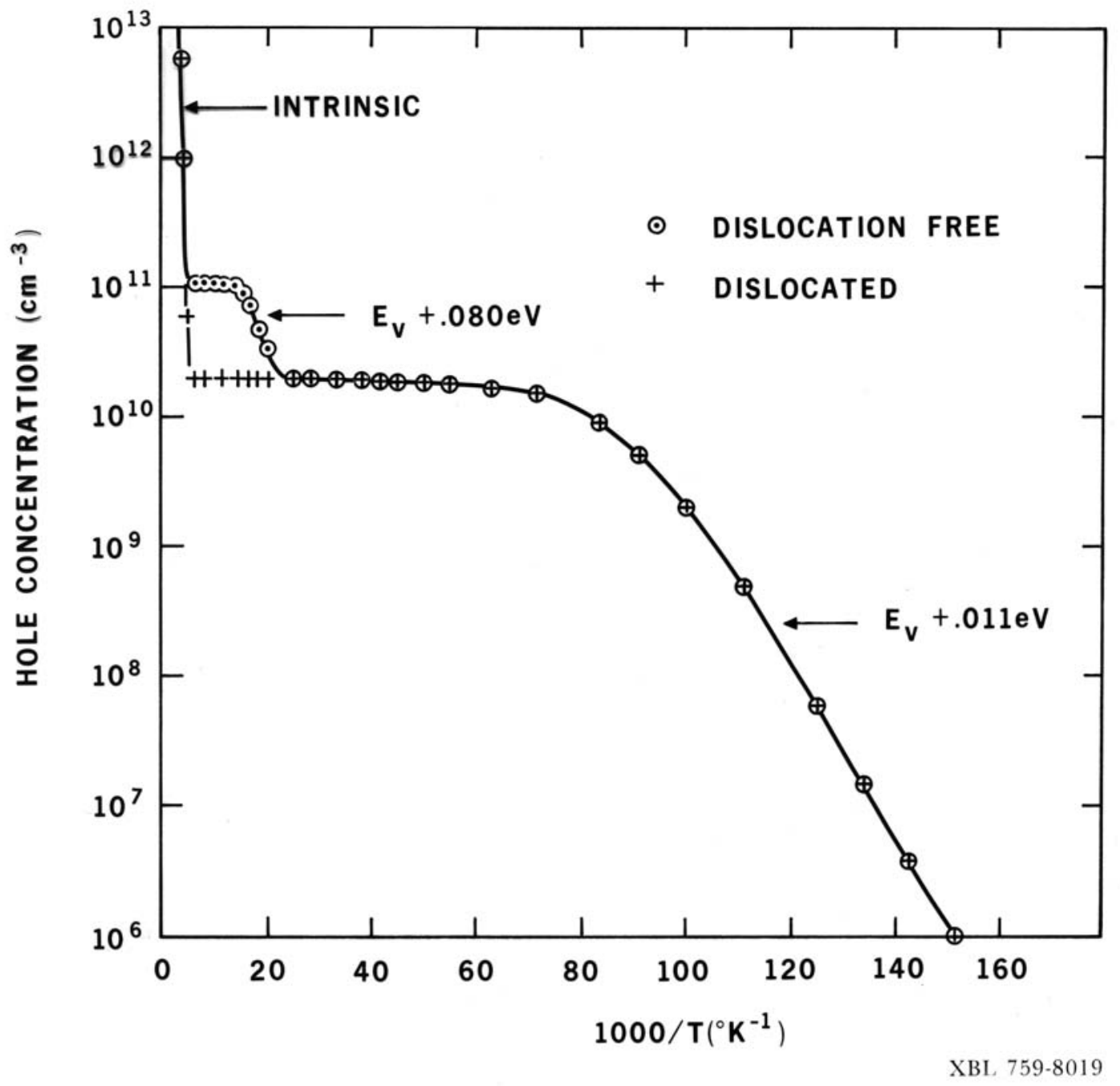

Figure 11. 


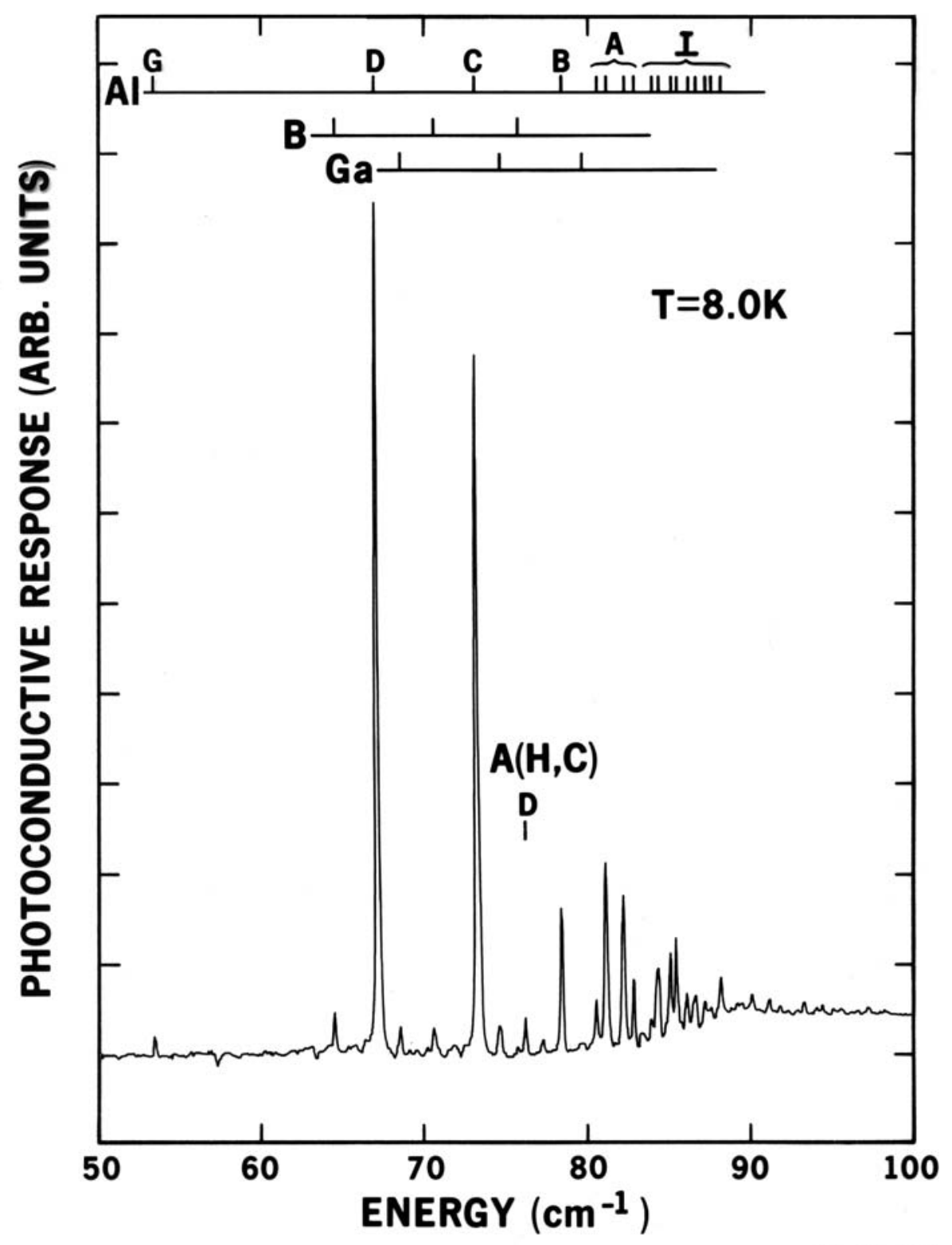

XBL 806-10176

Figure 12. 


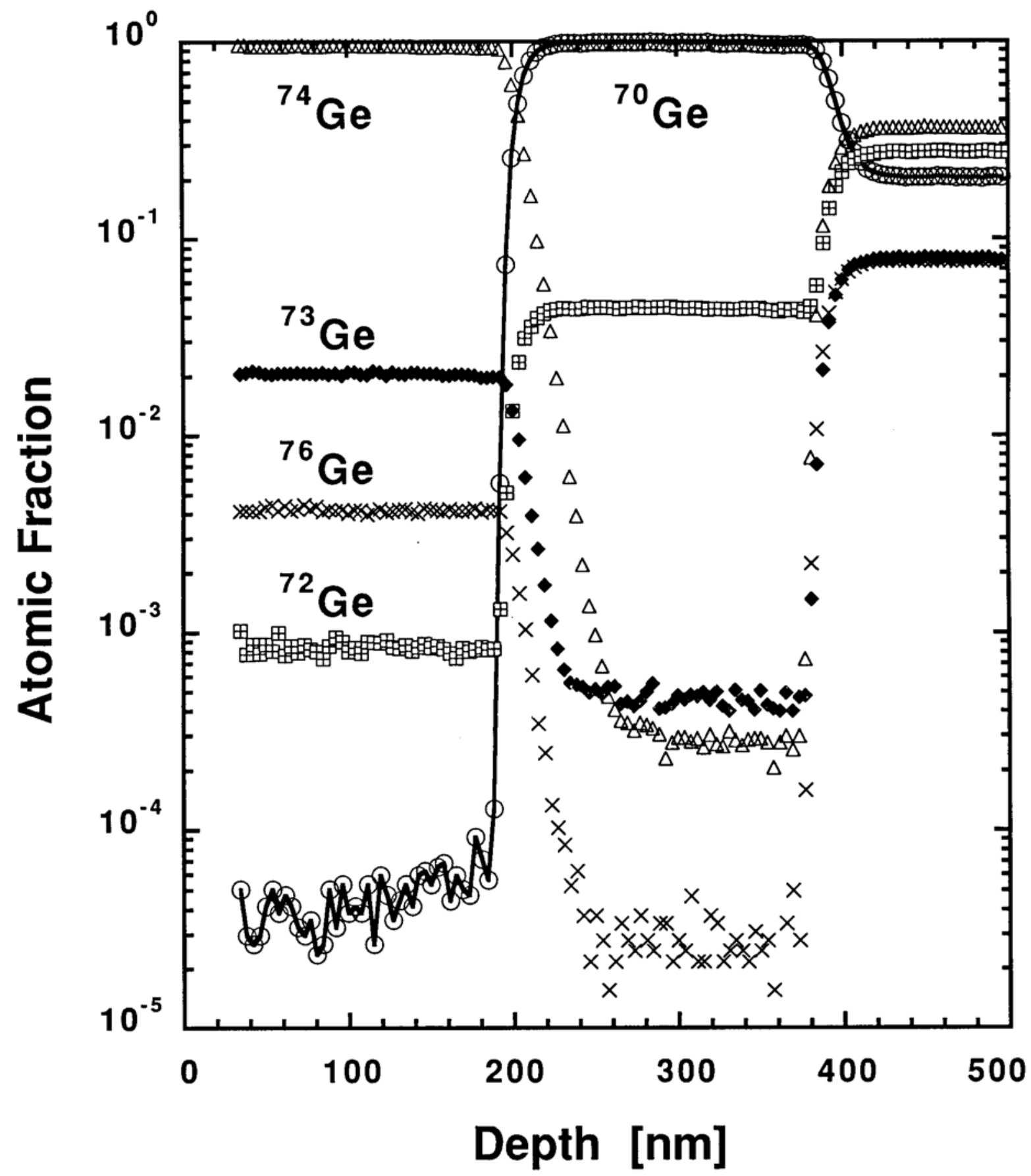

Figure 13a 


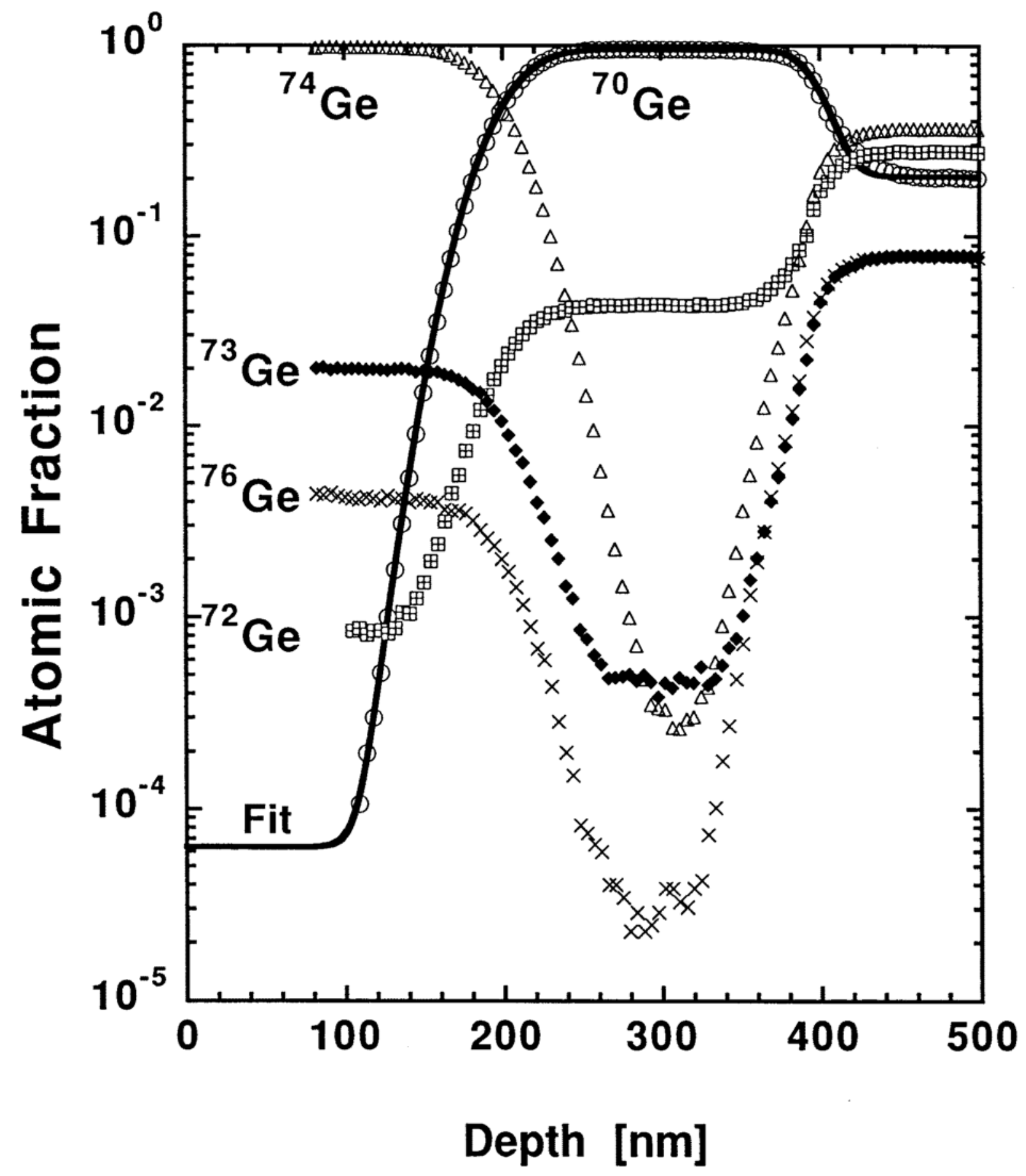

Figure 13b. 